\title{
PEMANFAATAN APLIKASI MICROSOFT POWERPOINT PADA SISWA SMP KELAS VIII DALAM PEMBELAJARAN KOORDINAT KARTESIUS
}

\author{
Sofia Nurul Hikmah' ${ }^{1}$, Sugama Maskar ${ }^{2}$ \\ Universitas Teknokrat Indonesia ${ }^{\mathbf{1 , 2}}$ \\ sofianurmah@gmail.com
}

\begin{abstract}
Received: Mei 2020
Accepted: Juni 2020

Abstract

Learning mathematics is very important for students, based on the learning objectives of mathematics in primary to secondary education, namely to prepare students to always develop logically, rationally, critically, accurately, honestly, efficiently and effectively in the world of education. The media can increase and direct the attention of students so that it can lead to learning motivation, more direct interaction between students and their environment and the ability of students to learn on their own according to their abilities. Therefore we need a learning media that can visualize objects from cartesian coordinate material. One such visual media is Power Point which can be used to visualize work objects from mathematics. This study aims to produce learning media that can be understood by students and to determine student interest in learning by using a microscope-based powerpoint learning media on cartesian coordinate material. The method used in research is research and development and the collection technique used is direct observation. The results of trials conducted, Microsoft PowerPoint based learning media were able to attract student interest in learning.
\end{abstract}

Published: Juni 2020

Keywords: Microsoft Powerpoint, cartesian coordinate.

\begin{abstract}
Abstrak
Pembelajaran matematika sangat penting bagi peserta didik, berdasarkan pada tujuan pembelajaran matematika di pendidikan dasar sampai menengah yaitu untuk mempersiapkan peserta didik dapat selalu berkembang secara logis, rasional, kritis, cermat, jujur, efisien dan efektif dalam dunia pendidikan. Media bisa meningkatkan dan mengarahkan perhatian peserta didik sehingga bisa menimbulkan motivasi belajar, interaksi yang lebih langsung antara siswa dan lingkungannya serta kemampuan siswa untuk belajar sendiri sesuai dengan kemampuannya. Oleh karena itu diperlukan sebuah media pembelajaran yang dapat memvisualisasikan objek-objek dari materi koordinat cartesius. Salah satu media visual tersebut adalah Power Point yang dapat digunakan untuk memvisualisasikan objek kerja dari matematika. Penelitian ini bertujuan untuk menghasilkan media pembelajaran yang dapat dipahami siswa dan untuk mengetahui minat belajar siswa dengan menggunakan media pembelajaran berbasis micrososft powerpoint terhadap materi koordinat kartesius. Metode yang digunakan dalam penelitian adalah research and development dan teknik pengumpulan yang digunakan adalah observasi lansung. Hasil uji coba yang dilakukan, media pembelajaran berbasis microsoft powerpoint ternyata mampu menarik minat belajar siswa.
\end{abstract}

Kata Kunci: Microsoft Powerpoint, Koordinat Kartesius. 
Sitasi artikel ini:

Hikmah, S.N. \& Maksar, S. (2020). Pemanfaatan Aplikasi Microsoft Powerpoint pada Siswa SMP Kelas VII dalam Pembelajaran Koordinat Kartersius. Jurnal Ilmiah Matematika Realistik, 1(1), 15-19

\section{PENDAHULUAN}

Matematika merupakan salah satu cabang ilmu pengetahuan yang dipelajari di sekolah (Puspaningtyas, 2019). Pembelajaran matematika sangat penting bagi peserta didik, Berdasarkan pada tujuan pembelajaran matematika dipendidikan dasar sampai menengah yaitu untuk mempersiapkan peserta didik dapat selalu berkembang secara logis, rasional, kritis, cermat, jujur, efisien dan efektif dalam dunia pendidikan (Masykur, dkk., 2018). Matematika merupakan ilmu dasar yang menjadi tolak ukur bagi perkembangan dan kemajuan ilmu pengetahuan dan teknologi (Ulfa, 2019). Menurut Ruseffendi (2006) banyak peserta didik yang setelah belajar matematika, tidak mampu memahami bahkan pada bagian yang paling sederhana sekalipun, banyak konsep yang dipahami secara keliru sehingga matematika dianggap sebagai ilmu yang sukar, ruwet dan sulit. Terlebih lagi pada materi koordinat kartesius, karena siswa dituntut untuk mampu membaca gambar letak titik koordinat dengan tepat. Untuk mempelajari materi tentang sistem koordinat, terlebih dahulu siswa harus menguasai konsep satuan dan pengukuran, urutan pada bilangan bulat, dan menggambar garis bilangan baik secara horizontal (datar) maupun vertikal (tegak) (Khaeroni, 2018).

Cara mengajar guru juga sangat mempengaruhi hasil belajar siswa. Masih banyak ditemui guru matematika yang mengajar dengan metode konvensional. Pembelajaran konvensional sering membuat siswa merasa bosan karena monoton. Akibatnya adalah ketika siswa dihadapkan pada tugas yang sulit dan membutuhkan kemampuan berfikir tingkat tinggi atau jawabannya tidak langsung diperoleh, maka siswa cenderung malas mengerjakannya, akhirnya dia menegosiasikan tugas tersebut dengan gurunya (Dewi \& Septa, 2019).

Dengan berkembangnya zaman yang ditandai kemajuan teknologi informasi berbasis internet dan robotik dengan nama revolusi industri 4.0 (Maskar, 2019), guru bisa memanfaatkan media dan teknologi dalam mengajar peserta didik. Seperti yang dikatakan oleh Achsin (1986) bahwa tujuan penggunaan media pengajaran adalah agar proses belajar mengajar yang sedang berlangsung dapat berjalan dengan tepat guna dan berdaya guna, untuk mempermudah bagi guru/pendidik dalam menyampaikan informasi materi kepada anak didik, untuk mempermudah bagi anak didik dalam menyerap atau menerima serta memahami materi yang telah disampaikan oleh guru. Sedangkan perkembangan teknologi dapat dijadikan solusi untuk berinovasi dalam bidang pembelajaran khususnya dalam pembuatan dan pengembangan media pembelajaran agar dalam proses pembelajaran lebih menarik yang berdampak pada minat belajar siswa (Saputra, 2019).

Media bisa meningkatkan dan mengarahkan perhatian peserta didik sehingga bisa menimbulkan motivasi belajar, interaksi yang lebih langsung antara siswa dan lingkungannya serta kemampuan siswa untuk belajar sendiri sesuai dengan kemampuannya. Oleh karena itu diperlukan sebuah media pembelajaran yang dapat memvisualisasikan objek-objek dari materi koordinat cartesius. Salah satu media visual tersebut adalah Power Point yang dapat digunakan untuk memvisualisasikan objek kerja dari matematika.

Microsoft power point merupakan salah satu program berbasis multimedia. Software ini, menyediakan fasilitas dalam bentuk slide-slide yang dapat membantu dalam menyusun suatu presentasi yang efektif, profesional, dan juga mudah. Sehingga memungkinkan para guru sekolah untuk memanfaatkan sebagai media pembelajaran (Azhar, 2017). Pada Power Point juga banyak fitur-fitur yang menarik seperti kemampuan pengolah teks, dapat menyisipkan gambar, audio, animasi, efek yang dapat di atur sesuai selera penggunanya, sehingga peserta didik akan tertarik pada apa yang ditampilkan pada Power Point (Misbahudin, dkk., 2018). Media pembelajaran koordinat cartesius berbasis power point ini diharapkan bisa membantu guru dalam proses belajar mengajar. Media ini juga diharapkan bisa meningkatakan hasil belajar siswa secara efektif.

\section{METODE}

Metode yang digunakan dalam penelitian ini adalah research and development. Research and Devolepment $(R \& D)$ adalah metode penelitian yang digunakan untuk menghasilkan produk tertentu dan menguji keefektifan metode tersebut (Hanafi, 2017). Dengan menggunakan metode ini diharapkan hasil belajar siswa meningkat. Subjek penelitian ini adalah siswa SMP kelas VIII berjumlah 5 siswa yang telah mempelajari materi koordinat kartesius. Langkah-langkah penelitian pengembangan menggunakan metode $R \& D$ dapat dilihat pada grafik 1 . 


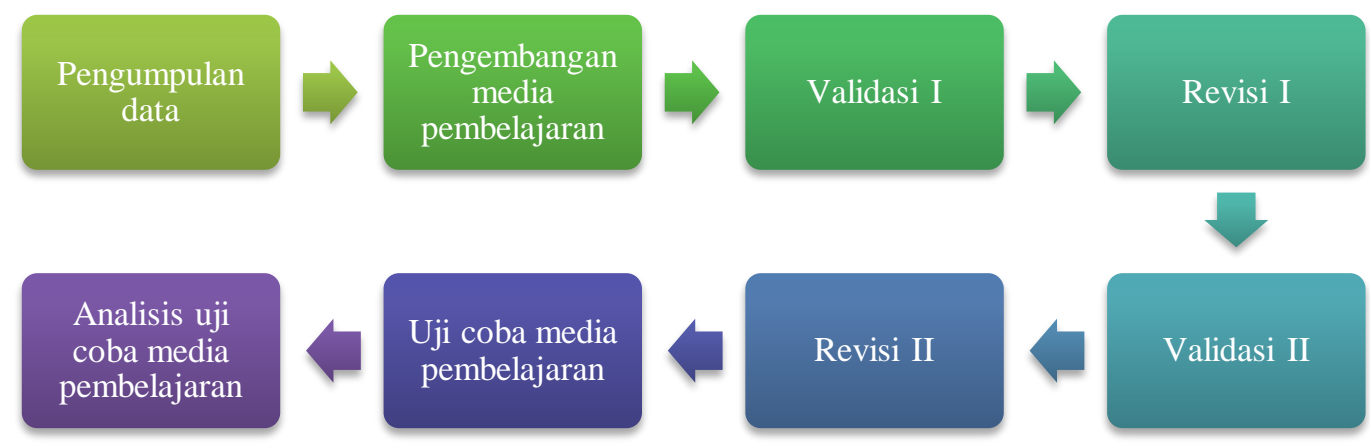

Gambar 1. Tahapan Penelitian

a. Pengumpulan data

Pengumpulan data pada penelitian ini menggunakan observasi langsung. Observasi merupakan teknik pengumpulan data, dimana peneliti melakukan pengamatan secara langsung ke objek penelitian untuk melihat dari dekat kegiatan yang dilakukan.

b. Pengembangan media pembelajaran

Media pembelajaran dibuat menggunakan microsoft power point. Media ini dibuat semenarik mungkin agar siswa tertarik untuk belajar sehingga meningkatkan hasil belajar siswa.

c. Validasi dan Revisi

Media pembelajaran berbasis microsoft powerpoint ini divalidasi oleh dua ahli matematika. Revisi media dilakukan berdasarkan saran dari kedua ahli tersebut.

d. Uji coba media pembelajaran

Uji coba dilakukan pada 5 siswa SMP kelas VIII. Uji coba media ini siswa akan melihat slide-slide yang ditayangkan dilaptop. Dalam uji coba yang dilakukan pada 5 siswa akan dilihat apakah media pembelajaran berbasis microsoft power point ini efektif untuk digunakan pada siswa SMP kelas VIII pada materi koordinat kartesius. Hasil dari uji coba didapatkan dengan melakukan observasi langsung dan wawancara singkat.

e. Analis uji coba media pembelajaran

Analisis uji coba dilakukan dengan menganalisa sederhana dari observasi langsung dan wawancara singkat.

\section{Teknik Analisis Data}

Penelitian yang digunakan adalah penelitian dan pengembangan (R\&D) (Saputra, 2019). Penelitian $R \& D$ adalah aktivitas riset dasar untuk mendapatkan informasi kebutuhan pengguna (needs assessment), kemudian dilanjutkan kegiatan pengembangan (development) untuk menghasilkan produk dan menguji keefektifan produk tersebut. Dalam penelitian ini menggunakan pendekatan $R \& D$ karena dalam penelitian ini akan menghasilkan produk yang berupa media pembelajaran interaktif (Asih \& Sabatari, 2015).

\section{HASIL DAN PEMBAHASAN}

Tujuan dari uji coba ini untuk mengetahui apakah siswa tertarik untuk belajar materi koordinat kartesius yang berbasis microsoft powerpoint. Penilaian dari uji coba ini adalah tentang penyajian media pembelajaran dan aspek kualitas materi pembelajaran dan tampilan pada media pembelajaran interaktif berbasis Microsoft powerpoint pada materi koordinat kartesius (Azhar, 2017). Proses pembelajaran dari media ini adalah materi dan latihan yang disajikan dalam bentuk slide.

Penelitian pengembangan yang dilakukan ini diarahkan untuk menghasilkan suatu produk yang berupa media pembelajaran interaktif berbasis microsoft powerpoint pada materi pembelajaran koordinat kartesius untuk meningkatkan proses pembelajaran maupun kompetensi siswa yang pada akhirnya diharapkan meningkatkan hasil belajar siswa (Azhar, 2017). Media pembelajaran ini sudah divalidasi oleh dua dosen matematika dan sudah direvisi berdasarkan saran kedua dosen tersebut. Rangkuman hasil validasi dan revisi dapat dilihat pada tabel 1. 
Tabel 1. Rangkuman Hasil Validasi dan Revisi

\begin{tabular}{|c|c|c|}
\hline & Validator I & Validator I \\
\hline Validasi I & $\begin{array}{l}\text { - Kurangi kalimat yang terlalu } \\
\text { penuh dalam } 1 \text { slide } \\
\text { - Tambahkan animasi }\end{array}$ & - \\
\hline Revisi I & $\begin{array}{l}\text { - Sudah jelas } \\
\text { - Sudah jelas }\end{array}$ & - \\
\hline Validasi II & - & $\begin{array}{l}\text { - Perbaiki latihan } \\
\text { - Perbaiki gambar }\end{array}$ \\
\hline Revisi II & - & $\begin{array}{l}\text { - } \text { Sudah jelas } \\
\text { - } \quad \text { Sudah jelas }\end{array}$ \\
\hline
\end{tabular}

Media pembelajaran berbasis microsoft powerpoint ini diuji coba pada 5 siswa SMP kelas VIII. Saya suka belajar dengan media powerpoint, karena terdapat gambar-gambar dalam slide yang memudahkan saya dalam mengingat [Siswa 1]. Tampilan dan animasi yang ada dalam slide membuat saya sangat tertarik dalam belajar [Siswa 2]. Belajar dengan media microsoft powerpoint tidak membosankan [Siswa 3]. Saya lebih semangat belajar dengan media microsoft powerpoint [Siswa 4]. Penggunaan microsoft powerpoint sangatlah praktis karena dapat digunakan secara berulang-ulang [Siswa 5].Setelah menguji coba produk dan wawancara singkat dapat disimpulkan bahwa kelima siswa tersebut sangat tertarik untuk belajar dengan menggunakan media pembelajaran berbasis microsoft powerpoint ini. Hasil dari uji coba media, siswa dapat memahami materi dan juga dapat menyelesaikan latihan yang terdapat dalam slide. Menurut 5 siswa yang melakukan uji coba bahwa materi dan tampilan pada media pembelajaran sudah sangat baik. Menurut mereka juga kegiatan pembelajaran menggunakan media ini sangat menarik dibandingkan dengan kegiatan pembelajaran konvensional. Proses uji coba media pembelajaran terhadap 5 siswa SMP dapat dilihat gambar 2.

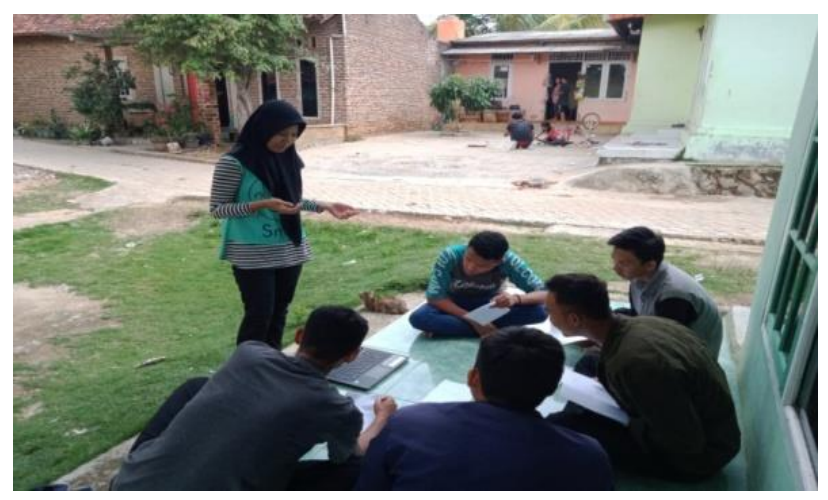

Gambar 2. Proses Uji Coba Media Pembelajaran

\section{SIMPULAN}

Berdasarkan hasil penelitian ini telah dihasilkan media pembelajaran berbasis microsoft powerpoint. Dalam melakukan uji coba media pembelajaran ini dapat berjalan dengan baik dengan menggunakan media pembelajaran ini dapat menarik minat belajar siswa sehingga mendapatkan hasil belajar yang memuaskan.

Adapun saran yang peneliti dapat sampaikan bahwa media pembelajaran berbasis microsoft powerpoint terhadap materi koordinat kartesius dapat digunakan oleh guru dalam kegiatan pembelajaran dan peneliti menyarankan agar penenlitian selanjutanya dapat mengembangkan media pembelajaran ini untuk diuji coba pada skala besar.

\section{REFERENSI}

Achsin, A. (1986). Media pendidikan dalam Kegiatan Belajar Mengajar. Institut Keguruan Ilmu Pendidikan Ujung pandang, Ujung pandang: 17-18. 
Asih, D.R., \& Sabatari, W. (2015). Pengembangan Media Pembelajaran Interaktif Pada Mata Pelajaran Promosi Statis di SMK N 1 Pengasih. Universitas Negeri Yogyakarta: Yogyakarta.

Azhar, Raqjabul. (2017). Pengembangan Media Pembelajaran Interaktif Berbasis Microsoft Power Point pada sistem Koordinat Kartesius: Akademi Komunitas Negeri Pidie Jaya.

Dewi, P. S., \& Septa, H.W. (2019). Peningkatan Kemampuan Pemecahan Masalah dan Disposisi Matematis Siswa dengan Pembelajaran Berbasis Masalah. Mathema: Jurnal Pendidikan Matematika. 1(1). 31-39.

Hanafi. (2017). Konsep Penelitian R\&D dalam Bidang Pendidikan. Jurnal Online Saintifika Islamica. 4(2). 129150.

Khaeroni dan Nopriyani, E. (2018). Analisis Kesulitan Belajar Siswa Kelas V SD/MI Pada Pokok Bahasan Sistem Koordinat. Jurnal Pendidikan Dasar Islam. 5(1). 76-93.

Maskar, S., \& Anderha, R.R. (2019). Pembelajaran Transformasi Geometri dengan Pendekatan Motif Kain Tapis Lampung. Mathema: Jurnal Pendidikan Matematika. 1(1). 40-47.

Masykur, R., Aulia, L.R., dan Sugiharta, I. (2018). Microsoft Powerpoint pada Aplikasi Android dalam Peningkatan Pemahaman Konsep Matematis, Jurnal Matematika dan Pembelajaran. 6(2), 265-273.

Misbahudin, D., dkk. (2018). Penggunaan Power Point Sebagai Media Pembelajaran: Efektifkah? Jurnal Wahana Pendidikan Fisika. 3(1). 43-48.

Puspaningtyas, N. D. (2019). Berpikir Lateral Siswa SD dalam Pembelajaran Matematika. Mathema: Jurnal Pendidikan Matematika. 1(1). 24-30.

Ruseffendi, E.T. (2006). Pengantar kepada Membantu Guru Mengembangkan Kompetensinya dalam pengajaran Matematika untuk CBSA. Bandung: Tarsito.

Saputra, V.H., \& Febriyanto, E. (2019). Media Pembelajaran Berbasis Multimedia untuk Anak Tuna Grahita. Mathema: Jurnal Pendidikan Matematika. 1(1). 15-23.

Ulfa, Marchamah. (2019). Strategi Preview, Question, Read, Reflect, Recite, Review (PQ4R) Pada Pemahaman Konsep Matematika. Mathema: Jurnal Pendidikan Matematika. 1(1). 48-55 